\title{
Prevention, Screening,
}

and Treatments for

\section{Obstructive Sleep Apnea:} Beyond Positive Airway

Pressure (PAP)

Editor

SONG TAR TOH

\section{SLEEP MEDICINE CLINICS}

www.sleep.theclinics.com

Consulting Editor

TEOFILO LEE-CHIONG Jr

March 2019 • Volume 14 - Number 1 